\title{
Exploration of the Critical Factors of Spa Tourism in Taiwan
}

\author{
Cheng Che Lin ${ }^{1}$, Lin Fang Chen ${ }^{1}$, Chi Min Wu ${ }^{2}$, Tso Jen Chen ${ }^{3, *}$ \\ ${ }^{1}$ Department of Applied English, Tainan University of Technology, Tainan, Taiwan \\ ${ }^{2}$ Department of Recreation and Health-Care Management, Chia Nan University of Pharmacy \& Science, Tainan, Taiwan \\ ${ }^{3}$ Department of Business Administration, Tainan University of Technology, Tainan, Taiwan
}

Email address:

tj0004@mail.tut.edu.tw (T. J. Chen)

${ }^{*}$ Corresponding author

\section{To cite this article:}

Cheng Che Lin, Lin Fang Chen, Chi Min Wu, Tso Jen Chen. Exploration of the Critical Factors of Spa Tourism in Taiwan. International Journal of Science, Technology and Society. Vol. 6, No. 2, 2018, pp. 47-51. doi: 10.11648/j.ijsts.20180602.14

Received: June 28, 2018; Accepted: August 1, 2018; Published: August 13, 2018

\begin{abstract}
The abundant natural resources in Taiwan enable the development of the tourism industry flourish; hot spring resource not only provides visitors taking a bath, but also becomes an exclusive tour spot. In the recent experiential tendency, travelers are more willing to consume the hot spring in a resort hotel and enjoy the beautiful and pleasant scenery at the same time. Therefore, the research designed the spa tourism for travelers to make their dreams come true and explored the relationships among these critical factors - experiential marketing, experiential value, satisfaction, and behavioral intention. Three hundred and twelve respondents in Tainan were randomly surveyed to gather data in the Guanzihling Hot Spring Scenic Area, Tainan City, Taiwan. The findings showed that experiential marketing have very significantly positive influence on behavioral intension, experiential value, satisfaction because the tourism of Guanzihling Hot Spring Scenic Area provides good itinerary planning, beautiful scenery, relaxing atmosphere, and luxury spa hotel for accommodation. Moreover, it displayed that the degree of satisfaction and behavioral intension are in pace with travelers' perception of experiential value. Finally, applying personal information to measure these variables, it revealed that spa tourism is a popular leisure activity for Taiwanese people. People who live more closely Guanzihling Hot Spring Scenic Area would be willing to do this spa tourism more frequently. Moreover, prime people (age 41-55) with characteristics of business job, higher annual income, and married people have stronger feeling of experiential marketing and value to spa tourism. Therefore, tourism industry should design a VIP itinerary, including luxury hotel, pretty or magnificent scenery, and gourmet food to upgrade or improve their satisfactory extent and ensure their revisits or recommendations.
\end{abstract}

Keywords: Spa Tourism, Experiential Marketing, Experiential Value, Satisfaction, Behavioral Intention

\section{Introduction}

Taiwan has many special geographical resources; especially some geothermal energy has nurtured natural hot springs in some Taiwan regions. These hot springs are mostly located in the valleys and form unique hot spring tourism that not only provides the public with bathing activities but also promotes hotel industry boomed in these areas. Therefore, tourism industry has been researching different marketing strategies of being a resort of recreation. Recently, tourism industry is focusing on experiential tendency. Visitors desire to experience the spa and beautiful natural scenery; in addition, spa hoteliers want to build their brand uniqueness to attract visitors to revisit.
Guanzihling Hot Spring is a mud hot spring in Tainan, also called "The Best Spiritual Spring in the world." It's regarded as a natural source of beauty treatment. Guanzihling Hot Spring nearby attractions include Red Maple Park, Fire and Water Spring, Huoshan Temple, Guanzilin Dasian Temple, Baihe Reservoir, Guanziling climbing routes, and so on. They formed a so-called Guanzihling Hot Spring Scenic Area. Hot springs apply water to bring pleasure and health, and can treat many diseases. Humans apply hot spring spas to health care and have been recognized by experts and scholars. Because the hot spring tourism has the functions of sightseeing, health and relaxation, it leads to the boom of participating in spa tourism. The core value of traveling is to provide travelers impressive experience and wonderful landscapes, and makes 
them realize the value of traveling. Further, this spa tourism would become their innermost unforgettable memory in their lives. Therefore, the research aims to explore the relationships among these critical factors - experiential marketing, experiential value, satisfaction, and behavioral intention, and then provides practical suggestions for tourism industry.

\section{Literature Review}

\subsection{Experiential Marketing}

Schmitt (1999) [1] asserted that the strategic experiential modules was the strategic basis of experiential marketing. Its purpose was to create different forms of experiential experience for customers, including sensory experiences (SENSE); affective experiences (FEEL); creative cognitive experiences (THINK); physical experiences, behaviors and lifestyles (ACT); and social-identity experiences that result from relating to a reference group or culture (RELATE). The sensory experience is based on the sensation of visual, auditory, olfactory, taste, and tactile. The five sensations create a sensory experience that triggers the customer's motivation and increases product value. The affective experience touches the customer's internal emotion and sentiment and is to create an affective experience. The thinking experience is a creative way to enable consumers to create cognitive and problem-solving experiences. The action experience is a tangible experience of life style and interaction with the body. The relation experience is that the individual is associated with the ideal self, other persons, or social culture. Furthermore, it makes the brand relate with the social cultural environment, having an impact on the potential community members. Some research argued cogently that experiential marketing brings business marketing more smoothly or successfully, such as branding food tourism, museum tourism, and so on (Tsai \& Wang, 2016; Kuo, Tien, \& Chang, 2017) [2, $3]$. In accordance with the research purpose, some research hypotheses are posed as follows:

Hypothesis 1: Experiential marketing would have significantly positive relationship with behavioral intension

Hypothesis 2: People who perceive more experiential marketing to spa tourism would have stronger experiential value

Hypothesis 3: Experiential marketing would have significantly positive relationship with traveler satisfaction.

\subsection{Experiential Value}

Blackwell, Miniard, and Engel (2006) [4] pointed out that experience value is the tangible product value and service perceived by the customer through the experience process, and the intangible emotional value exceeds the value expected by the customer. Immersing the customer in the context of consumption is an experiential event that leaves a deep impression on the customer. In other words, it will exceed the time and money the consumer invests in. It is a desired result through satisfying with someone's searching for pleasure. It comes from the experience of consuming products or service, resulting in hedonic value (Holbrook, 1996) [5].

According to Mathwick, Malhotra and Rigdon's (2001) [6] statement, it depicted four types of experiential value: (1) consumer return on investment: customers can experience the feedback expressed by economic utility; (2) service excellence: consumers can recognize the professional knowledge and service performance by service provider; (3) aesthetics: the aesthetic sense is derived from the reactive source, such as, visual, mental, and intrinsic graceful attraction; (4) playfulness: it reflects customers intrinsic delight coming from experiencing the product he purchased. From different research, the results indicated different research themes could significantly influence varied types of experiential value (Kim \& Stepchenkova, 2018; Ahn, Hyun, \& Kim, 2017) [7, 8]. In accordance with the research purpose, some research hypotheses are posed as follows:

Hypothesis 4: The investigator who has stronger experiential value would lead to more positive traveler satisfaction.

Hypothesis 5: The investigator who perceives more experiential value would lead to more positive behavioral intension.

\subsection{Satisfaction}

Ostorn and Iacobuci (1995) [9] pointed out the definition of customer satisfaction as consumer pay and reward is a cognitive behavior, emphasizing the results of evaluation and comparison. Customer satisfaction is the assessing results of comparison of customers' purchasing payment and reward. Williams and Soutar (2009) [10] archived past research and stated that there are cognitive service quality and value constructs, and emotional satisfaction is the pre-positioning factor; and value perception is more likely to affect satisfaction than service quality. The empirical results also showed that the value of money has greater influence on satisfaction than the value of emotion and novelty. Since there are many intangible characteristics in the tourism and hospitality service industry, the customer's emotional response is used as a measure of satisfaction. Likewise, the tangible service environment also requires the customer's cognitive judgment. Therefore, the customer satisfaction of the study includes both emotion and cognition. Moreover, Chou (2009) [11] demonstrated that the value of experience has a positive effect on customer satisfaction. It means that the higher the value of customer experience, the more satisfied customers are. Through experience, it can create great value. That is, through the stimulation of the senses, emotions, thinking, and actions, it can actually increase the whole value (Chien \& Huang, 2010) [12]. In accordance with the research purpose, some research hypotheses are posed as follows:

Hypothesis 6: Traveler satisfaction has significantly positive relationship with behavioral intension.

\subsection{Behavioral Intention}

Behavior intention is behavioral tendencies on customers' after-purchasing behavior to product or business. Therefore, 
scholars often apply behavior intention to evaluate individual behavior. The Customers' travel images and travel experiences on tourism spots have directly impact on revisiting and recommending (Castro, Armario \& Ruiz, 2007) [13]. Chi and Qu (2008) [14] thought high satisfaction is the final target for marketing but behavior intention is a further predictor than satisfaction. Ha and Jang (2009) [15] conducted the research on behavior intention, and sorted it into three aspects of revisiting, recommend and willing to pay. Lee and Chen (2010) [16] found that the experiential value will affect satisfaction; satisfaction will affect the willingness to revisit; satisfaction will increase the willingness to return (Kim \& Um, 2016; Liu, Tsou, \& Lo, 2012) [17, 18]. In accordance with the research purpose, one research hypotheses are posed as follows:

Hypothesis 7: Personal background would be significantly related to behavioral intension

\section{Research Method}

Customers would take into consideration a lot of factors that could influence their behavioral intentions when deciding to proceed a spa tourism. This study aims to investigate the factors of making a decision by future travelers, and also observes how each different characteristic influences on them. In accordance with the research purposes, some research hypotheses were posed as follows in order to analyze the interactive influences and relationships of main factors. Furthermore, T-test (Levene method) and Anova analyses (Scheffe method) are applied to measure hypotheses significance. Therefore, the research model is showed as Figure 1:

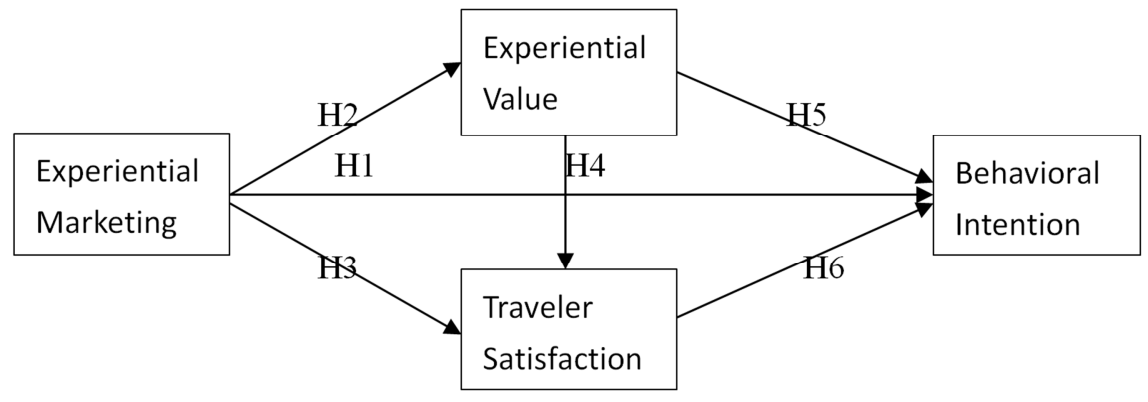

Figure 1. Framework of Critical Factors of Spa Tourism.

Data was collected randomly from 312 people in in the Guanzihling Hot Spring Scenic Area, Tainan City, Taiwan. The instrumentation used in this research is "Perception of Spa Tourism in Guanzihling Hot Spring Questionnaire (PSTGHSQ)" which has 5 main sections. The First section is Personal Information, and other sections are in the format of a typical five-level Likert Scale. Other sections are displayed as following: 1) Experiential Marketing; 2) Experiential Value; 3) Travel Satisfaction; and 4) Behavioral Intention. The section of Experiential Marketing is divided into 5 subsections, and the section of Experiential Value consists of
4 subsections. Table 1 shows that the values of Pearson Correlations of Four Main Variables are among 0.5 to 0.7 , predicting that these variables have positive, significant, and intermediate level of correlation. These values identify adequate levels of reliability and construct validity. Furthermore, the value of Cronbach's $\alpha$ of these four main variable sections sequentially are $0.932,0.946,0.917$, and 0.855 . The values of Cronbach $\alpha$ are all above 0.8 , so the measurement scales of the PSTGHSQ have very good reliability.

Table 1. Pearson Correlations of Four Main Variables.

\begin{tabular}{lllll}
\hline & Experiential Marketing & Experiential Value & Travel Satisfaction & Behavioral Intention. \\
\hline Experiential Marketing & 1 & & & \\
Experiential Value & $0.647^{* *}$ & 1 & 1 & 1 \\
Traveler Satisfaction & $0.503^{* *}$ & $0.630^{* *}$ & $0.663^{* *}$ & 1 \\
Behavioral Intention. & $0.547^{* *}$ & $0.611^{* *}$ & & \\
\hline
\end{tabular}

**means $\mathrm{p}$ value is smaller than 0.001

\section{Result and Discussion}

A total amount of 312 travelers was collected to do the survey questionnaire and run data analyses. The personal data of most respondents is displayed as following: (1) The gender of sex is male (56\%); (2) The age is between 41 to 55 years old (38\%); (3) the educational background is college (51\%); (4) current job is business $(41 \%)$, service industry (22\%) followed by; (5) average annually income is from NT $\$ 600,000$ to NT $\$ 1,000,000(41.3 \%)$; had been to anyone of spa tourism is $91.3 \%$; their residential area is Southern Taiwan (55.7\%); and marriage status is married occupied $67.1 \%$.

For "Hypothesis 1: Experiential marketing would have significantly positive relationship with behavioral intension", the results depict that the methods and designs of experiential marketing have very critically positive influence on behavioral intension. Next, for "Hypothesis 2: People who had perceived experiential marketing to spa tourism would have stronger experiential value", the F value for whole 
section of marketing experiences measured by ANOVAs is 9.54, $\mathrm{p}<0.05$ that means experiential marketing has significantly positive relation with traveler's experiential value. Therefore, the more successful experiential marketing to spa tourism, the higher experiential value tourists have. Next, for "Hypothesis 3: people who have more experiential marketing would have significantly positive relationship with traveler satisfaction", the result $(\mathrm{F}=7.06, \mathrm{p}<0.05)$ of ANOVA (Scheffe method) portrays that experiential marketing has significantly positive relation with traveler satisfaction. The tourism of Guanzihling Hot Spring Scenic Area provides good itinerary planning, beautiful scenery, relaxing atmosphere, and luxury spa hotel for accommodation; therefore, the degree of satisfaction would rise along with.

Some conclusions are made based on the above results of data analyses. First, in the subsection of sensory experiences, most respondents strongly agree or agree about that the Guanzihling Hot Spring Scenic Area has pretty and magnificent scenery and the air from flowers and trees makes travelers feel refreshed. The architectural style of Spa hotel building is attractive and makes people feel interested when watching its advertisements on TV or the Internet; 2) in the subsection of affective experience: the spa tourism creates an atmosphere of comfort and relaxation to visitors. The hotel reception staffs show kind and enthusiastic attitude for tenants; 3) in the thinking experiences subsection: the itinerary planning of Guanzihling Hot Spring makes people perceive the nice management of local government and creativity and intentions of the local tourist industry. The design of hotel websites would affect customers' impression of the hotel; 4) in the subsection of action experience: the advertisements from diverse mass communication stimulate travelers to conduct spa tourism of Guanzihling Hot Spring Scenic Area. The actual scenery and hotel facilities are exactly in line with the contents described by local government, travel industry, website, and so on. The travelers would like to take pictures to leave them as souvenirs for the duration of the journey; and 5) in the subsection of relation experience: the scenery and hotel of Guanzihling Hot Spring Scenic Area would lead to associations with other spring water areas and hotels. People could imagine the travel atmosphere through the information getting from different channels before heading off Guanzihling Hot Spring Scenic Area.

For "Hypothesis 4: The investigator who has stronger experiential value would lead to more positive traveler satisfaction", the result of ANOVA $(\mathrm{F}=8.41, \mathrm{p}<0.05)$ displays that the degree of satisfaction is in pace with travelers' perception of experiential value. Next, for "Hypothesis 5: The investigator who perceives more experiential value would lead to more positive behavioral intension", the $p$ value is smaller than 0.05 , predicting that traveler's experiential value positively influences their behavioral intension. In addition, for "Hypothesis 6: Travelers satisfaction have significantly positive relationship with behavioral intension", the result of $\operatorname{ANOVA}(\mathrm{F}=11.76, \mathrm{p}<0.05)$ reveals that better traveler satisfaction would cause the positive effect on behavioral intension.

On account of the results of the above statistical analyses, the experiential value actually has very great extent of traveler satisfaction and behavioral intension. It reflects that tourism industry should nurture customers' value by focusing on some of the items of the experience value section in the period of tourism of Guanzihling Hot Spring Scenic Area. For example, the price of the package tourism has round affordability and value, the service quality generated by service personnel more superior than customers are being paid to do, the leader of the spa hotel in the neighborhood, the style and design of the spa hotel, the scenery of these attractions, the process of tourism was filled with joy, the relaxation result in forgetting the annoying worry and trouble, and so on. Furthermore, the higher value in return on investment (ROI) and excellent service subsection of experiential value would lead to significantly stronger willingness to recommendation and repurchase.

For "Hypothesis 7: Personal background would be significantly related to behavior intension of spa tourism", it shows that age and annual income have significant difference related to behavioral intension because the results of ANOVAs (Scheffe method) for these two variables show that their $p$ values are both smaller than 0.05 . The expenses of spa tourism include fees for eating, traffic, and accommodation that occupies largest portion; particularly, living in a spa hotel is a luxury product for people. Therefore, these people who are older and have higher annual income would be more willing to do spa tourism based on their personal financial abilities. On the contrary, applying T-test (Levene method) to exam sex independent variable, the value $(F=3.23, p>0.05)$ displays that sex variable does not have significantly difference in behavior intension. Finally, the results of ANOVAs show that there is no significant difference related to their behavioral intension when personal background variables of education, current job, marriage status, people who have been to anyone of spa tourism, and residential area are tested to measure their relationship with behavior intension. This information predicts that spa tourism is a popular leisure activity for Taiwanese people.

At last, personal information is applied to measure the influence for the sections of experiential marketing and experiential value. Through ANOVAs (Scheffe method), it exhibits that age, annual income, residential area, and people who have been to anyone of spa tourism signify significantly difference between sections of experiential marketing. Similarly, age, occupation, annual income, residential area, people who have been to anyone of spa tourism, and frequency of spa tourism all demonstrate significantly difference between sections of experiential value. These results point out that people who live more closely to Guanzihling Hot Spring Scenic Area would willing to do this spa tourism more frequently. Moreover, prime people (age 41-55) with characteristics of business job, higher annual income, and married status have stronger feeling of experiential marketing and value to spa tourism. Therefore, tourism industry should endeavor to draw up VIP itinerary, 
find luxury hotel, and gourmet food to upgrade or improve their consumers' satisfactory extent and ensure travelers revisits or recommendations.

\section{Conclusion}

The results indicated that the more successful experiential marketing customers feel, the higher extent of experiential value, satisfaction, and more behavioral intensions. The customers perceive more experiential value, and then satisfaction and willingness of revisit or recommendation raise immediately afterwards. The experiential value has strongly impact on customer satisfaction; particularly, travel agencies should create very good ROI for travelers. The spa tourism should consist of beautiful scenery, attractions, experiential activities, shopping, food, and luxury resort hotel with relaxing atmosphere. Furthermore, the promotions or channels have to focus on the prime and business people in order hurriedly to grasp the targeting market. The government or travel industry, consequently, would like to reference the results of the study to their legislations of preserving hot spring, public policies, marketing planning, product design, and celebration holding. The study also gives further ideas of segmentation of potential consumers and develops proper activity promotions and marketing strategies for relevant agencies.

\section{References}

[1] Schmitt, B. (1999). Experiential Marketing. Journal of Marketing Management. 15 (1) p. p. 53-67.

[2] Tsai, C. T. \& Wang, Y. C. (2016). Experiential value in branding food tourism. Journal of Destination Marketing \& Management. Retrieved from http://dx.doi.org/10.1016/j.jdmm.2016.02.003.

[3] Kuo, Y. K., Tien, H. K., \& Chang, B. L. (2017). A Study on the Relationship among Public Participation, Experiential Marketing, Tourism Image and Benefits of Leisure of Taipei and Kaohsiung Museum of Fine Arts. Taiwan Journal of International Business Studies. 11 (2), pp. 165-183.

[4] Blackwell, R. D., Miniard, P. W., \& Engel, J. F. (2006). Consumer Behavior, Thomson/South-Western Publication.

[5] Holbrook, M. B. (1996). Customer Value: a Framework for Analysis and Research. Advances in Consumer Research, 23, pp. 138-142.

[6] Mathwick, C., N. K. Malhotra, \& E. Rigdon (2001). Experiential Value: Conceptualization, Measurement and Application in the Catalog and Internet Shopping Environment. Journal of Retailing, 77 (1), pp. 39-56.
[7] Kim, M. S. \& Stepchenkova, S. (2018). Examining The Impact of Experiential Value on Emotions, Self-Connective Attachment, and Brand loyalty in Korean Family Restaurants. Journal of Quality Assurance in Hospitality \& Tourism, 19 (3). Retrieved from https://doi.org/10.1080/1528008X.2017.1418699.

[8] Ahn, Y. J., Hyun, S. S. \& Kim, I. (2017). Vivid-Memory Formation Through Experiential Value in The Context of The international Industrial Exhibition. Journal of Travel \& Tourism Marketing. 34 (3). Retrieved from https://doi.org/10.1080/10548408.2016.1156617.

[9] Ostorm, A., \& Iacobucu, D. (1995). Consumer Trade-Offs and the Evaluation of Services, Journal of Marketing, 59 (14), P. 17-28.

[10] Williams, P., \& Soutar, G. N. (2009). Value, satisfaction, and behavioral intentions inan adventure tourism context. Annals of Tourism Research, 36 (3), pp. 413-438.

[11] Chou, H. J. (2009). The effect of experiential and relationship marketing on customer value: A case study of international American casual dining chains in Taiwan. Social Behavior and Personality, 37 (7), pp. 993-1007.

[12] Chien, T. W., \& Huang, C. F. (2010). A Study of the Relationships among the Theme Park Tourists' Experiential Value, Customers' Satisfaction and Recreation Effects. Leisure \& Holisic Wellness, 10 (1), pp. 1-37.

[13] Castro, C. B., Armario, M. E., \& Ruiz, M. D. (2007). The influence of market heterogeneity on the relationship between a destination's image and tourists' future behavior. Tourism Management, 28 (1), pp. 175-187.

[14] Chi, C. G., \& Qu, H. (2008). Examining the structural relationships of destination image, tourist satisfaction and destination loyalty: An integrated approach. Tourism Management, 29, pp. 624-636.

[15] Ha, J., \& Jang, S. C. (2009). Perceived values, satisfaction, and behavioral intentions: the role of familiarity in Korean restaurants. International Journal of Hospitality Manage, pp. $1-12$.

[16] Lee, M. J. \& Chen, Y. C. (2010). Relationships among Experiential Value, Travel Satisfaction and Revisiting Willingness on Tourists Who Participated in Penghu Island Tourism-A Case of Ji-bai and Cei-Mei Islands. Journal of Leisure and Recreation Industry Management, 3 (1), pp. 1-18.

[17] Kim, S. M. \& Um, K. H. (2016). The Effects of Ambivalence on Behavioral Intention in Medical Tourism. Asia Pacific Journal of Tourism Research, 21 (9), pp. 1020-1045.

[18] Liu, Y. L., Tsou, C. T., \& Lo, Y. L. (2012). Identification of Tourists' Travel Motivations, Perceived Values and Loyalty of Religious Tourism - An Empirical Study Based on Beigang Chaotian Temple. Journal of Humanities and Social Sciences, 8 (2), pp. 1-17. 